\title{
The genetics of arsenate tolerance in Yorkshire fog, Holcus lanatus L.
}

\author{
MARK R. MACNAIR, QUINTON J. CUMBES AND ANDREW A. MEHARG \\ Department of Biological Sciences, Hatherly Laboratories, University of Exeter, Prince of Wales Road, \\ Exeter EX4 4PS, U.K.
}

\begin{abstract}
The genetics of arsenate tolerance in Holcus lanatus is investigated. Three tolerant plants from an abandoned arsenic mine, and three non-tolerant plants and one less tolerant plant (C9) from an uncontaminated site were crossed. Five polycrosses between plants from $F_{1}$ crosses between mine and non-tolerants were set up. Four polycrosses between tolerant $F_{2}$ progeny, and four polycrosses between non-tolerant $F_{2}$ progeny, were established. A polycross involving the progeny of a single tolerant plant allowed to cross at random with a normal population was also established. The results are broadly compatible with a single-gene model for tolerance, with tolerance being dominant. The majority of $F_{2}$ crosses segregated in to 3:1 ratios, and backcrosses gave 1:1 ratios. The crosses between $C 9$ and non-tolerants gave 1:1 ratios, which suggests that the less tolerant $C 9$ was heterozygous for tolerance. All crosses between non-tolerants gave all non-tolerant offspring. In one cross a major gene for albinism also segregated, and linkage of the tolerance gene to this gene ( $r . f .=35 \%$ ) was demonstrated. A number of families produced progeny ratios incompatible with the simple major gene model. Possible causes of these anomalous crosses are discussed and it is suggested that the tolerance gene may show variable penetrance depending on the genetic background.
\end{abstract}

Keywords: arsenate tolerance, genetics, modifiers, penetrance.

\section{Introduction}

Heavy metal tolerance is one of the classic examples of micro-evolution and adaptation (Shaw, 1990). While there have been many studies to show that tolerance is a heritable character, there have been rather few investigations into the detailed genetics of this phenomenon (see Macnair, 1990, for a review). In particular, one area of controversy concerns the number of genes involved in producing the adaptation. Traditionally (e.g. Bradshaw \& McNeilly, 1981) it has been suggested that this character is normally evolved polygenically. Macnair (1990) argues that in most of the studies published in this field it is not possible to differentiate between polygenic and major gene control. Because of the innate inaccuracies of tolerance testing, it will normally be necessary to do detailed progeny testing in order to identify major genes if they are present. Macnair (1983) was able to show, by this technique, that there was a major gene for copper tolerance in Mimulus guttatus, and has argued (Macnair, 1990) that there is some evidence for a major gene for copper tolerance in Agrostis capillaris. Recently, Schat \& ten
Bookum (1992) have shown that copper tolerance in Silene vulgaris is also probably determined by a major gene. Watkins \& Macnair (1991) suggest that arsenate tolerance in Agrostis capillaris may be subject to major gene control, but were unable to do sufficient crosses to show this conclusively. In this paper we investigate the genetics of arsenate tolerance in Holcus lanatus, a self-incompatible perennial grass, $2 n=14$ (Beddows, 1961), which was first shown to exhibit arsenate tolerance by Porter \& Peterson (1977).

\section{Materials and methods}

\section{Provenance of plants}

The crosses described in this paper are derived from three tolerant plants (G2, G21, G12) originally collected from the Gawton United mine in the Tamar Valley (map ref. SX452688) and four collected from the University of Exeter campus (C9, C16, C19, C20). Of these, C16, C19 and C20 were non-tolerant, but $C 9$ showed partial tolerance in a full dose-response curve (see Macnair \& Cumbes, 1987). Prior to the work 
reported here, all plants had been maintained in normal soil for over 3 years in the glasshouse.

\section{Crossing}

\section{PAIR CROSSES}

Generation 1. All pairwise crosses between the seven plants were attempted. Not all crosses produced viable seeds, particularly those involving the plant C9. Selfs of all genotypes were attempted to confirm incompatibility.

Generation 2. Various $\mathrm{F}_{2}$ and backcrosses to both mine and non-tolerant plants were set up from the $F_{1} s$. Further crosses between $\mathrm{C} 9$ and non-tolerants were performed. The cross $\mathrm{C} 20 \times \mathrm{C} 19$ produced an anomolous result in generation 1 (see below) and was therefore repeated six times. There was a period of very hot weather during the peak of the flowering season which resulted in reduced seed set but most crosses gave some viable seeds. However, not one of the C20 $\times$ C19 crosses gave any seed, which suggests that this cross is incompatible. It is therefore probable that this anomalous cross in generation 1 was caused by an invalid cross (incompatible crosses are particularly vulnerable to contamination by stray pollen).

Plants to be crossed were planted outside in pots over winter in order to vernalize. In March/April they were brought into the glasshouse. Crosses were effected by bagging inflorescences together in a glassine envelope. The envelope was kept vertical with cane supports and shaken daily to distribute pollen. The flag leaves of bagged spikes were removed to reduce humidity within the bags. The bags were removed after flowering had been completed to allow seed maturation to take place. The cross is described as female parent $\times$ male parent for all crosses.

\section{RANDOM CROSSES}

Pair crosses always produce a rather small number of seeds. On the assumption that most plants in Exeter would be non-tolerant (an assumption that later turned out to be false) ramets of the three tolerant plants were also planted out in various places on the campus in order to cross randomly with the local population. It was hoped that this technique would produce large quantities of $F_{1}$ seed very easily. In the event, these crosses suffered from vandalism and accidental damage, and only one produced seeds. This family is called G21 Ext.

\section{POLYCROSSES}

Generation 2. Six polycrosses were established, five involving $F_{1}$ plants and one the progeny of G21 Ext.
Generation 3. Eight polycrosses were established, four involving the non-tolerant offspring of four of the $F_{2}$ produced from the generation 2 polycrosses, and four the tolerant offspring of the same crosses.

All polycrosses involved between eight and 20 individuals. Plants to be included in a polycross were vernalized as for pair crosses. They were subsequently planted out in random positions in a square array of approximately $1 \times 1 \mathrm{~m}$, and the array surrounded by clear polythene sheeting to a height of about $2 \mathrm{~m}$, to minimize the amount of extraneous pollen falling on the polycross. Individual polycrosses were separated by at least $25 \mathrm{~m}$. In the first series of polycrosses the individual plants were planted too close together and grew extremely vigorously, so that it proved impossible to separate the seed from the individual parents with certainty. In the second series, the plants were smaller and better spaced. This series was grown in the summer of 1989 and some of the polycrosses were badly affected by the drought of that summer, so that some plants died, and others produced few inflorescences.

The pair crosses involved only single inflorescences, and produced between 2 and 128 seeds (median 25, interquartile range 9-50). Most plants involved in polycrosses produced many inflorescences. Every seed obtained was sown and tested for tolerance for all paircrosses, and for all polycrosses that produced less than about 200 seeds. In other polycrosses, only a sample was tested.

\section{Tolerance testing}

Preliminary studies (Macnair \& Cumbes, 1987) have shown that the differences in root growth between tolerant and non-tolerant plants is very large and thus it was not necessary to calculate tolerance indices as has been used in many tolerance studies (Wilkins, 1978). Two methods were used to test tolerance in this study.

(a) Testing adult plants. Seeds were sown on John Innes No. 2 compost, and transferred into small $6 \mathrm{~cm}$ or smaller) pots. When at the $2-3$ tiller stage, 2 or 3 tillers were removed and rooted in $1 / 10$ strength Rorisons solution (Hewitt, 1966) minus phosphate and with arsenate at $0.133 \mathrm{~mm}$. The longest root on each tiller was measured after 2 weeks. Some non-tolerant tillers died within hours in this test; some survived to produce short roots $(1-30 \mathrm{~mm})$. Tolerant tillers normally produce roots longer than $40 \mathrm{~mm}$.

(b) Testing seedlings. A seedling testing technique was developed, modifying a technique originally devised by Ingram (1987) and Symeonidis et al., (1985). Seeds were sown onto filter paper moistened with distilled 
water. On the third day, germinating seeds were transferred onto a layer of alkathene beads floating on the surface of $1 / 10$ strength Rorisons solution minus phosphate and with arsenate at $0.133 \mathrm{~mm}$, in $200 \mathrm{ml}$ polystyrene coffee cups. Only seedlings with a radicle of less than $1 \mathrm{~mm}$ were chosen. This technique ensures that all seedlings are initially similar, and removes any variation in root length caused by the day of germination from the final root length. The pots were kept on the windowsill of the laboratory for 7 days, and the root length of the seedlings measured. Survivorship of seedlings was consistently over 99 per cent. Seedlings with root lengths less than $10 \mathrm{~mm}$ were classified as non-tolerant; $11 \mathrm{~mm}$ or more as tolerant (see Fig. 1). Many experiments were conducted to check the optimum day to measure roots, the repeatability of the results, and the effect of environmental variation. It might be considered odd to classify all seedlings with root lengths from $11 \mathrm{~mm}$ to more than $70 \mathrm{~mm}$ as one category, tolerant, but in fact there is no evidence that this variance in root length reflects anything more than the normal variance in root length caused by genetic and environmental effects. Figure 2 compares the range of root lengths of seedlings from the same families tested at the same time as either arsenate solution or a control solution without arsenate. It is clear that, compared to the control, the arsenate separates out a class of short rooted individuals (non-tolerants), and causes a reduction in mean of the root lengths of other individuals (tolerants) but the variance of the tolerant individuals in arsenate is similar $(C V=0.33)$ to the variance of the same families in control solution $\langle C V=0.46)$.

It is important to note that neither of these testing techniques is sufficiently precise to differentiate between degrees of tolerance (i.e. C9 would be scored the same as a mine plant).

\section{Results and discussion}

\section{Generation 1}

Table 1 gives the data from all $F_{1}$ crosses between the seven plants that produced any viable seeds. In general, all crosses with one of the parents as a mine plant produce all tolerant offspring. All crosses between the three non-tolerant plants produce non-tolerant offspring, while crosses between the partially tolerant C9 and the three non-tolerant plants segregate. There were two apparently anomalous crosses that do not fit this pattern: $\mathrm{C} 19 \times \mathrm{G} 2$ segregate (the reciprocal did not) and C20 $\times$ C19 gave almost all tolerants. Repeats of this cross in the next season failed to produce any seed, which suggests that this cross is incompatible, so this anomaly is probably caused by an illicit cross (see Materials and Methods).

\section{Generation 2}

Pair crosses. The data from the $\mathrm{F}_{2} \mathrm{~s}$, backcrosses and crosses to C9 are given in Table 2. The backcrosses to mine plants give primarily all tolerants. With the excep-
Fig. 1 Histogram giving the root lengths of all the seedlings tested by the seedling testing method included in this paper.

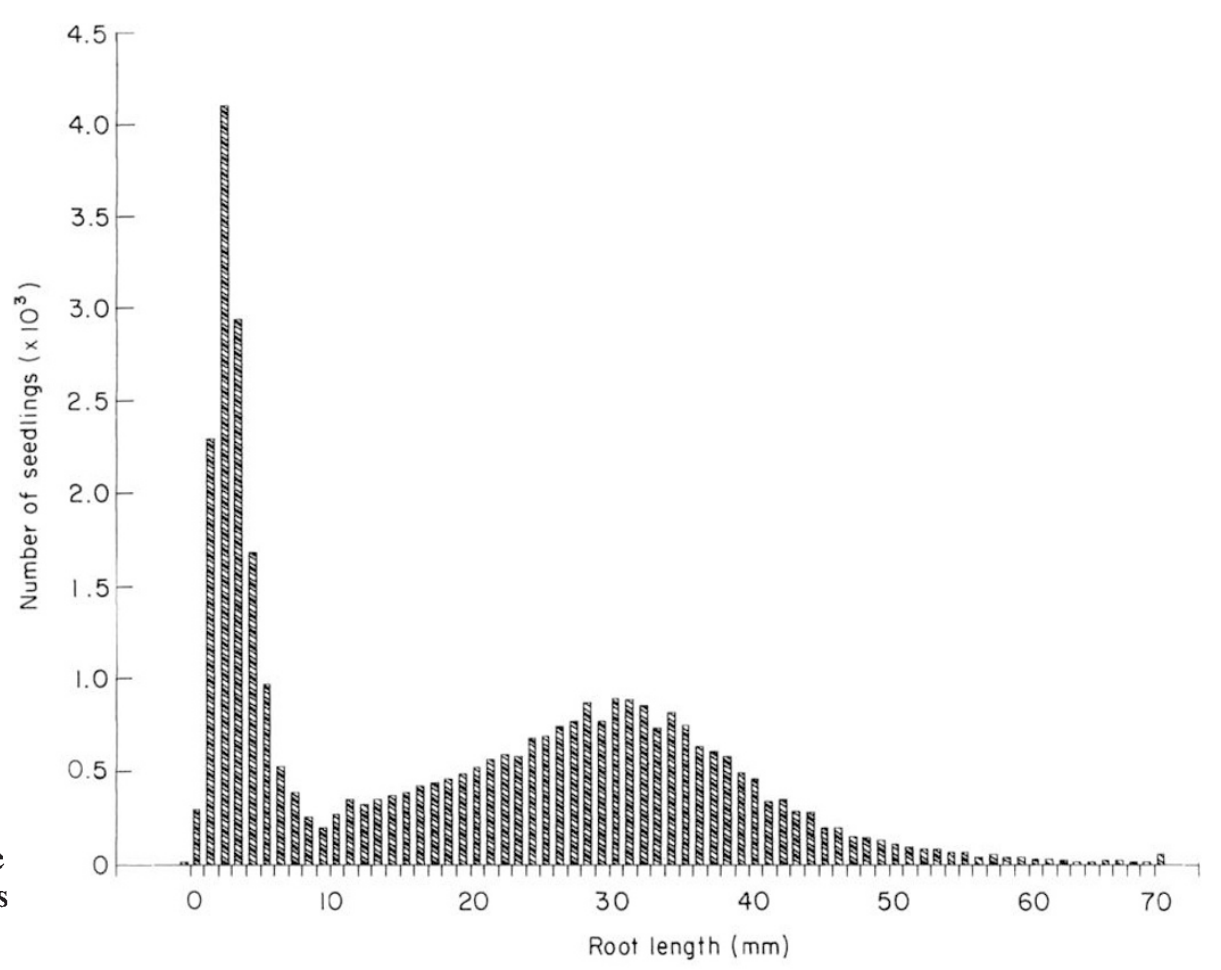




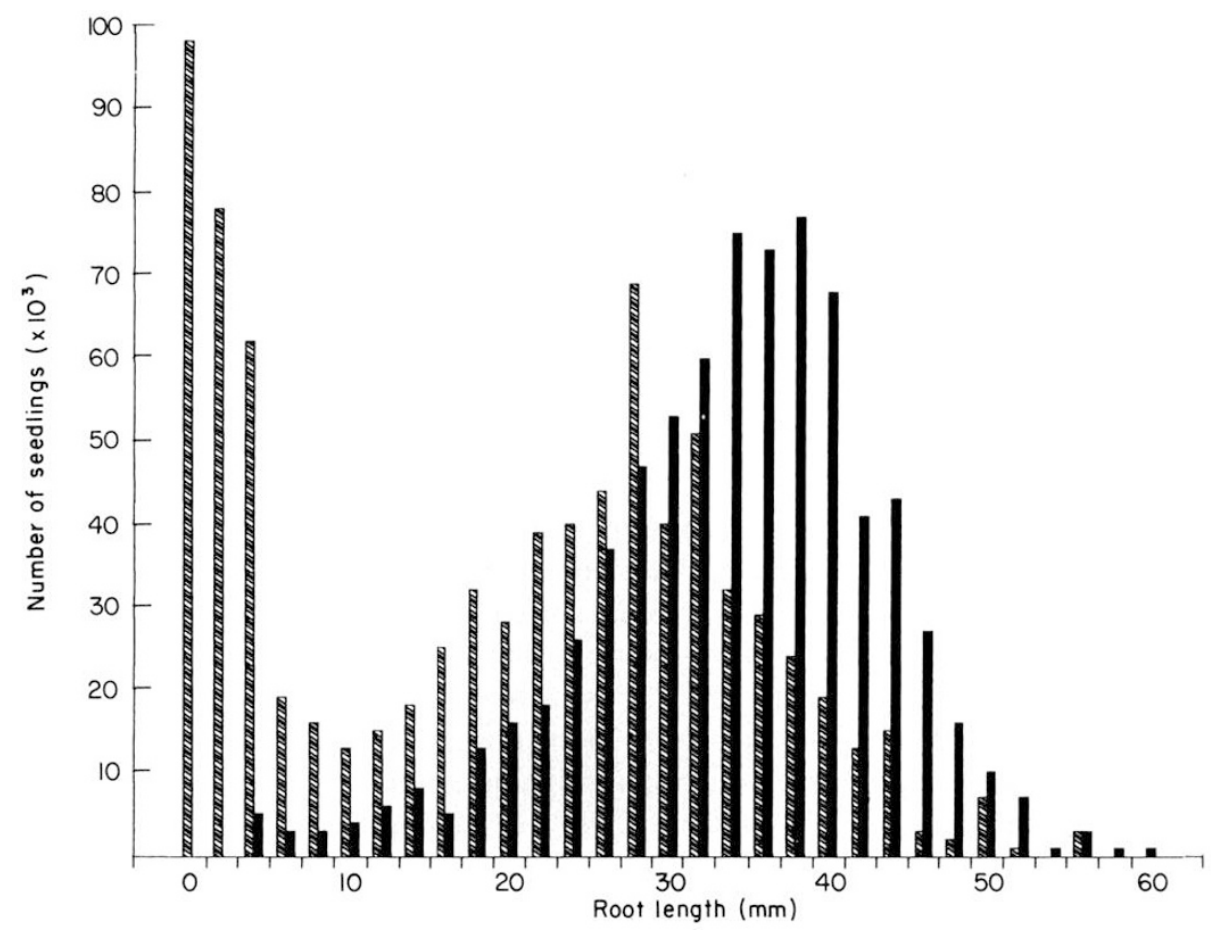

Fig. 2 Histograms of root lengths of individuals from 15 different segregating families tested simultaneously by the seedling testing method in both arsenate solution (hatched bars), and a control solution lacking arsenate (solid bars).

Table 1 Numbers of tolerant and non-tolerant offspring produced by crosses between three mine plants and four campus plants. The ratios are given as T:NT, and are the total number of seedlings produced in each family. A dash indicates that no viable seed was produced

\begin{tabular}{lllllllll}
\hline & \multicolumn{2}{l}{ Male parent } & & & & & \\
\cline { 2 - 5 } & G2 & G12 & & G21 & C16 & C19 & C20 & C9 \\
\hline Female parent & & & & & & & \\
G2 & $\mathrm{X}$ & $97: 0$ & - & $146: 5$ & $153: 3$ & $110: 0$ & - \\
G12 & $23: 1$ & $\mathrm{X}$ & $25: 1$ & $61: 0$ & $80: 0$ & $30: 0$ & $29: 0$ \\
G21 & - & $92: 1$ & $\mathrm{X}$ & - & $35: 3$ & $13: 1$ & - \\
C16 & $88: 9$ & $20: 2$ & $51: 3$ & $\mathrm{X}$ & - & $0: 32$ & - \\
C19 & $62: 47$ & $138: 0$ & $10: 0$ & - & $\mathrm{X}$ & $138: 9$ & - \\
C20 & $89: 5$ & $68: 0$ & - & $0: 130$ & $23: 0$ & $\mathrm{X}$ & - \\
C9 & $10: 0$ & $18: 2$ & $56: 0$ & $17: 9$ & $8: 8$ & $25: 33$ & $\mathrm{X}$ \\
\hline
\end{tabular}

tion of one family, the backcrosses to non-tolerants give approximately $1: 1$ segregations, although the overall segregation, even if the anomalous cross is excluded, departs significantly from a 1:1 segregation $\left(114: 140, \chi^{2}=4.55, P<0.05\right)$. Most of the $\mathrm{F}_{2} \mathrm{~s}$ show approximately $3: 1$ ratios, with the exception of two involving a $(\mathrm{C} 19 \times \mathrm{G} 2)$ parent, and two involving a $(\mathrm{C} 20 \times \mathrm{C} 19)$ parent. One of the $(\mathrm{C} 20 \times \mathrm{C} 19)$ plants was the same individual as that which produced the anomalous backcross family. With the four anomalous crosses excluded the overall ratio does not deviate from the 3:1 ratio predicted by a single gene segregation $\left(369: 132, \chi^{2}=0.48, \mathrm{~ns}\right)$. The two crosses to C9 that produced seed, although small, were also consistent with a $3: 1$ ratio $\left(41: 19, \chi^{2}=1.42, \mathrm{~ns}\right)$. With a few exceptions, therefore, the results of the pair crosses suggest that a single gene model, with the tolerant allele being dominant, may be appropriate. There is no evidence for a difference between reciprocal crosses so there is no indication of any maternal effect.

Crosses involving C9. Unfortunately C9 regularly showed rather poor fertility, so the number of successful crosses to this interesting genotype were not as great as we had intended, and the number of progeny obtained was often not very large. However, inspection 
Table 2 Numbers of tolerant and non-tolerant progeny produced in pair crosses in the second generation. $\chi^{2}$ het $=2 \times 2$ contingency $\chi^{2}$ for difference between reciprocal crosses; $\chi^{2}$ rat $=\chi^{2}$ testing for departure from predicted ratio $\left(3: 1\right.$ for $F_{2}$ crosses; 1:1 for backcrosses to non-tolerant plants)

\begin{tabular}{|c|c|c|c|c|c|c|c|c|}
\hline & \multicolumn{2}{|c|}{ Cross } & \multicolumn{4}{|c|}{ Reciprocal Total } & \multirow{2}{*}{$\begin{array}{l}\chi^{2} \\
\text { het }\end{array}$} & \multirow{2}{*}{$\begin{array}{l}\chi^{2} \\
\text { rat }\end{array}$} \\
\hline & $\mathrm{T}$ & NT & $\mathrm{T}$ & NT & $\mathrm{T}$ & NT & & \\
\hline \multicolumn{9}{|l|}{ Backcross tolerant $F_{1}$ to mine plants } \\
\hline $\mathrm{G} 12 \times(\mathrm{C} 19 \times \mathrm{G} 2)^{20}$ & 82 & 4 & 15 & 1 & 97 & 5 & - & - \\
\hline $\mathrm{G} 2 \times(\mathrm{C} 19 \times \mathrm{G} 2)^{11}$ & 6 & 0 & 35 & 5 & 41 & 5 & - & - \\
\hline $\mathrm{G} 2 \times(\mathrm{C} 19 \times \mathrm{G} 12)^{24}$ & 31 & 4 & 31 & 4 & 62 & 8 & - & - \\
\hline $\mathrm{G} 12 \times(\mathrm{C} 19 \times \mathrm{G} 12)^{20}$ & 19 & 2 & 12 & 1 & 31 & 3 & - & - \\
\hline Six other crosses & 71 & 6 & - & - & - & - & - & - \\
\hline Total & & & & & 302 & 27 & & \\
\hline \multicolumn{9}{|l|}{ Backcross non-tolerant $F_{1}$ to mine plants } \\
\hline Five crosses & & & & & 206 & 6 & & \\
\hline \multicolumn{9}{|l|}{$F_{2}\left(\right.$ tolerant $F_{1} \times$ tolerant $\left.F_{1}\right)$} \\
\hline$(\mathrm{C} 19 \times \mathrm{G} 2)^{19} \times(\mathrm{C} 19 \times \mathrm{G} 2)^{20}$ & 68 & 26 & 21 & 7 & 89 & 33 & 0.1 & 0.3 \\
\hline$\langle\mathrm{C} 20\rangle$ & 42 & 11 & 50 & 25 & 92 & 36 & 2.4 & 0.6 \\
\hline$(\mathrm{C} 20 \times \mathrm{G} 12)^{21} \times(\mathrm{C} 20 \times \mathrm{G} 12)^{16}$ & 18 & 3 & 11 & 8 & 29 & 11 & 3.9 & 0.4 \\
\hline$(\mathrm{C} 20 \times \mathrm{G} 12)^{17} \times(\mathrm{C} 20 \times \mathrm{G} 12)^{12}$ & 9 & 2 & 47 & 20 & 56 & 22 & - & 0.4 \\
\hline$(\mathrm{C} 20 \times \mathrm{C} 19)^{22} \times(\mathrm{C} 19 \times \mathrm{G} 2)^{15}$ & 16 & 28 & 41 & 44 & 57 & 72 & 1.7 & 65.8 \\
\hline$(\mathrm{C} 20 \times \mathrm{G} 2)^{12} \times(\mathrm{C} 19 \times \mathrm{G} 2)^{15}$ & 22 & 29 & 9 & 8 & 31 & 37 & 0.5 & 31.4 \\
\hline$(\mathrm{C} 20 \times \mathrm{C} 19)^{17} \times(\mathrm{C} 20 \times \mathrm{C} 19)^{22}$ & 24 & 21 & 60 & 31 & 84 & 52 & 2.0 & 12.7 \\
\hline$(\mathrm{C} 19 \times \mathrm{G} 12)^{20} \times(\mathrm{C} 19 \times \mathrm{C} 20)^{23}$ & 9 & 4 & 34 & 24 & 43 & 28 & - & 7.9 \\
\hline Six other crosses & 103 & 30 & - & - & 103 & 30 & - & 0.4 \\
\hline Total (all cr & & & & & 5843 & 321 & - & 52.9 \\
\hline Total (excluding 4 significant crosses) & & & & & 369 & 132 & - & 0.5 \\
\hline \multicolumn{9}{|l|}{$\mathrm{C} 9 \times$ tolerant $\mathrm{F}_{1}$} \\
\hline $\mathrm{C} 9 \times(\mathrm{C} 19 \times \mathrm{G} 2)^{20}$ & 19 & 11 & - & - & 19 & 11 & - & 2.2 \\
\hline $\mathrm{C} 9 \times(\mathrm{C} 20 \times \mathrm{C} 19)^{23}$ & 22 & 8 & - & - & 22 & 8 & - & 0.0 \\
\hline \multicolumn{9}{|l|}{ Backcross tolerant $F_{1} \times$ non-tolerant } \\
\hline$(\mathrm{C} 20 \times \mathrm{C} 19)^{2.3} \times \mathrm{C} 20$ & 1 & 1 & 7 & 33 & 8 & 34 & - & 16.1 \\
\hline$(\mathrm{C} 20 \times \mathrm{C} 19)^{2.3} \times(\mathrm{C} 16 \times \mathrm{C} 20)^{18}$ & 33 & 22 & - & - & 13 & 22 & - & 2.3 \\
\hline Ten other crosses & 50 & 58 & - & - & 50 & 58 & - & 0.6 \\
\hline Total $(a$ & & & & & 118 & 178 & - & 12.2 \\
\hline Total (excluding 1 significant & & & & & 110 & 144 & - & 4.6 \\
\hline $\begin{array}{l}\mathrm{C} 9 \times \text { non-tolerant } \mathrm{F}_{1} \\
\mathrm{C} 9 \times(\mathrm{C} 20 \times \mathrm{C} 16)^{17}\end{array}$ & 20 & 11 & - & - & 20 & 11 & - & 2.6 \\
\hline
\end{tabular}

of Tables 1 and 2 show that all the crosses are compatible with the hypothesis that $\mathrm{C} 9$ is a heterozygote, and produces all tolerant offspring in crosses to mine plants $(T T)$, 3:1 ratios in crosses to the $\mathrm{F}_{1}$ between mine plants and non-tolerants $(T t), 1: 1$ ratios in crosses to non-tolerants $(t t)$.

Polycrosses. The results of the five polycrosses involving $F_{1}$ families are given in Table 3 . As explained in the Materials and Methods, the seed could not be properly split into the separate female parents so that the 'packets' given in Table 3 only approximately refer to individual plants. If all the plants included in a polycross had a similar genotype, then this deficiency in the experiment would not matter: all the seed heads would produce a similar ratio, so it would not matter which parent they came from. If, on the other hand, there is some heterogeneity in genotype amongst the plants, then different areas of the polycross will produce different ratios, and the different packets should reflect this heterogeneity, even if, because of mixing, the exact ratio is difficult to interpret. 
Table 3 Polycrosses between $F_{1}$ plants of five crosses between mine plants and campus plants. Packets refers to packets of seed that more or less correspond to individual parents in the polycross (see Materials and Methods)

\begin{tabular}{|c|c|c|c|c|c|}
\hline Polycross & Packet & $\mathrm{T}$ & NT & $\chi^{2}$ rat & $\chi^{2}$ het \\
\hline \multirow[t]{12}{*}{$\mathrm{C} 19 \times \mathrm{G} 12$} & 1 & 136 & 51 & 0.515 & \\
\hline & 2 & 245 & 87 & 0.256 & \\
\hline & 3 & 145 & 36 & 2.521 & \\
\hline & 4 & 181 & 67 & 0.538 & \\
\hline & 5 & 117 & 29 & 2.054 & \\
\hline & 6 & 109 & 35 & 0.037 & \\
\hline & 7 & 95 & 35 & 0.256 & \\
\hline & 8 & 90 & 36 & 0.857 & \\
\hline & 9 & 113 & 32 & 0.664 & \\
\hline & 10 & 109 & 27 & 1.921 & \\
\hline & 11 & 131 & 34 & 1.700 & \\
\hline & Total & 1471 & 469 & 0.704 & 10.615 \\
\hline \multirow[t]{8}{*}{$\mathrm{C} 20 \times \mathrm{G} 12$} & 1 & 176 & 50 & 1.000 & \\
\hline & 2 & 123 & 45 & 0.284 & \\
\hline & 3 & 202 & 58 & 1.005 & \\
\hline & 4 & 219 & 61 & 1.543 & \\
\hline & 5 & 144 & 59 & 1.788 & \\
\hline & 6 & 132 & 46 & 0.067 & \\
\hline & 7 & 135 & 48 & 0.147 & \\
\hline & Total & 1131 & 367 & 0.200 & 5.269 \\
\hline \multirow[t]{5}{*}{$\mathrm{C} 20 \times \mathrm{G} 2$} & 1 & 156 & 52 & 0.000 & \\
\hline & 2 & 178 & 46 & 2.381 & \\
\hline & 3 & 187 & 53 & 1.089 & \\
\hline & 4 & 147 & 52 & 0.136 & \\
\hline & Total & 668 & 203 & 1.332 & 2.274 \\
\hline \multirow[t]{9}{*}{$\mathrm{C} 20 \times \mathrm{C} 19$} & 1 & 237 & 108 & $7.313^{* *}$ & \\
\hline & 2 & 188 & 74 & 1.471 & \\
\hline & 3 & 171 & 85 & $9.187^{* *}$ & \\
\hline & 4 & 149 & 61 & 1.835 & \\
\hline & 5 & 157 & 40 & 2.172 & \\
\hline & 6 & 96 & 32 & 0.000 & \\
\hline & 7 & 137 & 57 & 1.986 & \\
\hline & Total & 1135 & 457 & $11.66^{* * *}$ & 12.304 \\
\hline & Total without significant crosses & 727 & 264 & 1.421 & 6.043 \\
\hline \multirow[t]{11}{*}{$\mathrm{C} 19 \times \mathrm{G} 2$} & 1 & 157 & 162 & $113.1^{* * *}$ & \\
\hline & 2 & 208 & 148 & $52.1^{* * *}$ & \\
\hline & 3 & 162 & 91 & $16.2^{* * *}$ & \\
\hline & 4 & 230 & 118 & $14.7^{* * *}$ & \\
\hline & 5 & 210 & 124 & $26.2^{* * *}$ & \\
\hline & 6 & 185 & 127 & $41.0^{* * *}$ & \\
\hline & 7 & 164 & 144 & $77.6^{* * *}$ & \\
\hline & 8 & 339 & 282 & $138.0^{* * *}$ & \\
\hline & 9 & 231 & 159 & $51.7 * * *$ & \\
\hline & 10 & 78 & 67 & $34.8^{* * *}$ & \\
\hline & Total & 1964 & 1422 & $521.6^{* * *}$ & $43.8^{* * *}$ \\
\hline
\end{tabular}

$\chi^{2}$ rat: $\chi^{2}$ testing for a 3:1 ratio; $\chi^{2}$ het: heterogeneity $\chi^{2}$ from an analysis of $\chi^{2}$.

${ }^{* *} P<0.01$; ${ }^{* *} P<0.001$. All other $\chi^{2}$ values not significant at 0.05 level. 
Three of the polycrosses give homogenous ratios, which do not differ from 3:1 (Table 3). The other two, $(\mathrm{C} 19 \times \mathrm{G} 2)$ and $(\mathrm{C} 20 \times \mathrm{C} 19)$ appear to be heterogeneous. In the case of $(\mathrm{C} 20 \times \mathrm{C} 19)$, the heterogeneity is due to two packets which produce a ratio $(368: 184)$ which does not differ from the two anomalous $\mathrm{F}_{2}$ crosses produced by the $(\mathrm{C} 20 \times \mathrm{C} 19)$ plants in the pair crosses (heterogeneity $\chi^{2}=1.91$, d.f. 3 , ns). The other packets produce a $3: 1$ ratio $\left(609: 230, \chi^{2}=2.61\right.$, $\mathrm{ns})$. The other anomalous polycross $(\mathrm{C} 19 \times \mathrm{G} 2)$ produced both heterogeneous ratios and gave no indication of $3: 1$ ratio. The ratios shown by the two anomalous paircross $\mathrm{F}_{2} \mathrm{~s}$ involving this family are similar to those produced by the polycross.

The last polycross, G21 Ext, gave heterogeneous ratios, and departures from 3:1 ratios. However, the departures were in the direction of too many tolerants. Because of other features of the polycross, it was decided to repeat this properly in the following year, and so a polycross containing 20 individuals from this family was established. This polycross segregates not

Table 4 Results of a polycross between the $F_{1}$ progeny of G21 Ext. The progeny segregate both for tolerance and albinism. The genotype of each plant on the assumption that there's a single gene for each character is given, as well as the $2 \times 2 \chi^{2}$ testing the hypothesis that the T:NT ratio is the same in both green and white seedlings

\begin{tabular}{|c|c|c|c|c|c|c|c|}
\hline \multirow[b]{2}{*}{ Parent } & \multirow[b]{2}{*}{ Genotype } & \multicolumn{2}{|c|}{ Green } & \multicolumn{2}{|c|}{ Albino } & \multirow{2}{*}{$\begin{array}{l}2 \times 2 \\
\chi^{2}\end{array}$} & \\
\hline & & $\mathrm{T}$ & NT & $\mathrm{T}$ & NT & & \\
\hline 1 & $T t A A$ & 127 & 35 & 0 & 0 & - & \\
\hline 2 & $T t A a$ & 242 & 41 & 61 & 3 & $4.53^{*}$ & + \\
\hline 3 & $T t A a$ & 111 & 26 & 15 & 0 & 3.43 & + \\
\hline 4 & TtAa & 138 & 56 & 33 & 3 & $6.71^{* *}$ & + \\
\hline 5 & $T t A a$ & 102 & 83 & 29 & 11 & $4.08^{*}$ & + \\
\hline 6 & $T T A A$ & 138 & 2 & 0 & 0 & - & \\
\hline 7 & $T T A a$ & 574 & 39 & 72 & 6 & 0.83 & - \\
\hline 8 & $T t A a$ & 158 & 43 & 42 & 3 & $5.24^{*}$ & + \\
\hline 9 & TtAa & 122 & 54 & 26 & 6 & 1.21 & + \\
\hline 10 & $T t A a$ & 127 & 56 & 34 & 4 & $6.41^{*}$ & + \\
\hline 11 & $T t A a$ & 103 & 43 & 17 & 1 & $4.66^{*}$ & + \\
\hline 12 & TtAa & 132 & 49 & 32 & 3 & $5.49^{*}$ & + \\
\hline 13 & $T t A a$ & 85 & 35 & 19 & 2 & 3.56 & + \\
\hline 14 & $T t A A$ & 464 & 159 & 0 & 0 & - & \\
\hline 15 & $T t A a$ & 206 & 70 & 47 & 6 & $4.93^{*}$ & + \\
\hline 16 & TtAa & 52 & 32 & 23 & 2 & $8.13^{* *}$ & + \\
\hline 17 & $T T A A$ & 163 & 4 & 0 & 0 & - & \\
\hline 18 & $T t A A$ & 332 & 45 & 0 & 0 & - & \\
\hline 19 & $T T A A$ & 228 & 2 & 0 & 0 & - & \\
\hline 20 & $T t A A$ & 286 & 60 & 0 & 0 & - & \\
\hline
\end{tabular}

${ }^{*} P<0.05 ;{ }^{* *} P<0.01 ;+=$ Albino seedlings give higher T:NT ratio than green. only for tolerance but also for albino seedlings. The results for this family are given in Table 4 . Considering firstly the albino character, 13 of the 20 individuals segregate albino seedlings. If we assume that they have the genotype $A a$, and the other seven individuals are $A A$, then the pollen rain descending on a heterozygous individual will derive from seven $A A$ individuals and $12 A a$ individuals (only 12 because they are selfincompatible), and thus $a$ pollen will constitute $6 / 19$ or 0.316 of the total. Thus the seed of the heterozygous individuals should segregate $0.842: 0.158$. The total green: albino segregation amongst heterozygotes is 2779:500, with expected values, on the one gene hypothesis, of 2761.3:517.7 $\left(\chi^{2}=0.806, \mathrm{~ns}\right)$. It is thus clear that the albino character is governed by a single gene.

Considering now tolerance, three individuals, 6, 17 and 19 produce very few non-tolerant offspring and are clearly homozygous for tolerance. One other, number 7 , although producing 6.4 per cent non-tolerants, is clearly different from all the other segregating plants, and is also probably homozygous. Considering these four plants together, they have a mean rate of generation of non-tolerants of 2.8 per cent. For the moment let us assume that this is a measure of the error rate of tolerance testing in this polycross. Following a similar argument for tolerance as we did for green:albino segregation, and assuming that we have 4 $T T$ and $16 T t$ individuals, then the pollen rain on a heterozygous individual is $7.5 / 19$ or $0.395 t$. The segregation amongst heterozygous plants should then be $0.803: 0.197$. However, assuming that tolerants are miscored as non-tolerants with an error rate of 2.8 per cent in this family, then the predicted ratio should be $0.780: 0.220$. The observed ratio is $3001: 879$, with expected values, on the one gene hypothesis, of $3027.0: 853.0\left(\chi^{2}=1.06, \mathrm{~ns}\right)$.

Table 4 gives the $2 \times 2 \chi^{2}$ for each family segregating for both albinos and non-tolerants. With the exception of family 7 , the tolerants have a higher proportion of albinos than do the non-tolerants (this is further evidence that plant 7 is homozygous for the tolerance gene), and in nine out of 12 families this $\chi^{2}$ is significant. Everitt (1977) gives a method for combining the information in $n 2 \times 2$ contingency tables of this sort. The square root of the $\chi^{2}$ is given a sign depending on the direction of the deviation, and the statistic $Z=\Sigma \chi / \sqrt{ } n$ calculated. This statistic is distributed as a standard normal distribution. Using this method with these data we obtain $Z=6.77(P<0.001)$. Two possible causes of this association of albinism with tolerance are possible. Firstly, the albino phenotype could give arsenate tolerance pleiotropically. The non-tolerant albinos would then represent miscoring and it would further require that the miscoring ratio was substantially higher 
amongst these tolerants than amongst the other tolerant plants $(45 / 423,10.6$ per cent as opposed to an average of 2.8 , or 6.4 per cent for plant 7 ). Secondly, the two genes could be genetically linked. This hypothesis is preferred. The recombination fraction can be calculated from the proportion of albino nontolerant plants amongst the progeny of double heterozygotes. There are 12 AaTt individuals, so that of the compatible pollen landing on such a plant, $11 / 19$ were derived from other double heterozygotes. Of the pollen, a fraction $0.5 r$ will be $a t$, where $r$ is the recombination fraction between $T$ and $A$. at ovules will be produced at a frequency of $0.5 r$, so that the proportion of aat individuals will $11 / 19 \times(0.5 r)^{2}$. The proportion is $45 / 2589$, so that $r=0.35$, or $35 \mathrm{cM}$ (95 per cent confidence limits from 29.1 to 39.4 ).

This hypothesis therefore predicts that G21 was originally $A a T T$ and requires that, of the 20 progeny analysed here, 13 received an $a T$ gamete, and seven an $A T$ gamete from this plant. This ratio is compatible with the expected 1:1 segregation. It further requires that the pollen rain in Exeter should contain $A T$ gametes at a high enough frequency that $4 / 20$ progeny could be $T T$. In fact, samples of seed from the vicinity of the campus regularly produce a high proportion of arsenate-tolerant plants (Meharg \& Macnair, 1992b). The frequency of tolerant plants in a number of samples of the local population was 56 per cent; on the assumption of a single gene, this corresponds to a tolerant gene frequency of 34 per cent, which is compatible with the observed frequency of $T T$ individuals in this family.

\section{Generation 3}

The two $\mathrm{F}_{2} \mathrm{~s}[(\mathrm{C} 19 \times \mathrm{G} 2)$ and $(\mathrm{C} 20 \times \mathrm{C} 19)]$, which produce some results that apparently are incompatible with a single gene model, were analysed further by taking two $\mathrm{F}_{2}$ 'families' from each and growing up the progeny to produce $\mathrm{F}_{3} \mathrm{~s}$. The 'families' were separate 'packets' from the $F_{2}$ polycrosses. The progeny were tolerance tested and from each family two polycrosses were set up: one containing only tolerant progeny, and one containing only non-tolerant progeny. There was thus a total of eight polycrosses. On the single gene hypothesis, the non-tolerant polycrosses should produce no tolerant progeny, while the tolerant polycrosses should segregate with ratios that will depend on the proportion of $T T: T t$ parents within each polycross.

Non-tolerant polycrosses. In the four non-tolerant polycrosses, a total of 37 plants set seed, and of 5891 seedlings tested for tolerance, only 26 tested as tolerants. This is entirely consistent with the results of all pre- vious crosses between non-tolerants, which have all, with the sole exception of $\mathrm{C} 20 \times \mathrm{C} 19$ (which, as argued earlier, was probably an invalid cross), produced effectively 100 per cent non-tolerant offspring. This result is the single most persuasive argument against polygenic inheritance: it is almost impossible to conceive of a polygenic model for tolerance that could produce true breeding non-tolerants from the segregation of an $\mathrm{F}_{2}$.

Tolerant polycrosses. The data from the four tolerant polycrosses are given in Table 5. These families appear to fall broadly into two classes. Seven produce 12 per cent or less non-tolerant offspring; 30 families produce between 22 and 47 per cent non-tolerants. One family (family 3 of $\mathrm{C} 19 \times \mathrm{G} 2 / 3$ ) produced a proportion of 18 per cent. On the one gene model the first class would be families produced from homozygous plants, with heterozygous plants producing families with the greater proportion of non-tolerants. The postulated genotypes of each plant on this basis are also given in Table 5 . The proportion of homozygotes postulated on this model is rather less than the 2:1 ratio predicted under a single gene model, although not formally significantly less $\left(\chi^{2}=3.80, P \approx 0.05\right)$. However the classification of plant 1 of the $(\mathrm{C} 19 \times \mathrm{G} 2) / 3$ polycross is based on very few progeny (only a single inflorescence on this plant set seed) and must be suspect. If this plant is removed, the ratio $6: 31$ differs significantly from $2: 1\left(\chi^{2}=4.88\right.$, $P<0.05$ ).

Of the four polycrosses, two produce T:NT ratios that fit the one gene model. In $(C 20 \times C 19) / 3$, the seven heterozygotes produce a T:NT segregation of $704: 261$. The expected ratio, calculated on the basis that there are one TT and seven $T t$ plants in the polycross, and that the error rate is the same as for the $T T$ plant (7.9 per cent), is 702.2:262.8 $\left(\chi^{2}=0.017\right.$, ns $)$. The $(\mathrm{C} 19 \times \mathrm{G} 2) / 3$ polycross produces a $960: 319$ segregation from the eight definite heterozygotes. This ratio does not differ from $3: 1\left(\chi^{2}=0.002\right.$, ns): a 3:1 ratio would be predicted if we assume that plant 1 , which produced so little seed, also produced a negligible amount of pollen, and that the error rate of scoring was small. The other two polycrosses produced too many non-tolerants. In $(\mathrm{C} 20 \times \mathrm{C} 19) / 1$ there are four plants scored as $T T$, each of which produce about 10 per cent non-tolerants (the highest postulated miscoring rate). The seven $T t$ plants produce a total segregation of 915:385. The predicted ratio, calculated assuming a 10 per cent error rate, is 1073.3:226.7 $\left(\chi^{2}=133.9\right.$, $P<0.001)$. $(\mathrm{C} 19 \times \mathrm{G} 2) / 1$ produces a total segregation of 1705:765, which again differs from the predicted ratio (calculated using an error rate of 5 per cent) of 1825.0:645.0 $\left(\chi^{2}=30.2, P<0.001\right)$. 
Table 5 Results of four polycrosses between tolerant plants from $F_{1}$ polycrosses. The cross column gives the original cross, with the number following the solidus being the packet (see Table 3). The genotype of each plant on the single gene model is also given

\begin{tabular}{|c|c|c|c|c|}
\hline Cross & Plant & Genotype & $\mathrm{T}$ & NT \\
\hline \multirow[t]{10}{*}{$\mathrm{C} 19 \times \mathrm{G} 2 / 1$} & 1 & $T T$ & 204 & 3 \\
\hline & 2 & $T t$ & 177 & 105 \\
\hline & 3 & $T t$ & 402 & 214 \\
\hline & 4 & $T t$ & 292 & 82 \\
\hline & 5 & $T t$ & 192 & 88 \\
\hline & 6 & $T t$ & 132 & 45 \\
\hline & 7 & $T t$ & 117 & 37 \\
\hline & 8 & $T t$ & 114 & 67 \\
\hline & 9 & $T t$ & 143 & 64 \\
\hline & 10 & $T t$ & 136 & 63 \\
\hline \multicolumn{2}{|c|}{ Total segregating families } & & 1705 & 765 \\
\hline \multirow[t]{9}{*}{$\mathrm{C} 19 \times \mathrm{G} 2 / 3$} & 1 & $T T(?)$ & 9 & 0 \\
\hline & 2 & $T t$ & 56 & 19 \\
\hline & 3 & $T t$ & 162 & 36 \\
\hline & 4 & $T t$ & 92 & 40 \\
\hline & 5 & $T t$ & 180 & 56 \\
\hline & 6 & $T t$ & 86 & 38 \\
\hline & 7 & $T t$ & 192 & 59 \\
\hline & 8 & $T t$ & 132 & 53 \\
\hline & 9 & $T t$ & 60 & 18 \\
\hline \multicolumn{3}{|c|}{ Total segregating families } & 960 & 319 \\
\hline \multirow[t]{11}{*}{$\mathrm{C} 20 \times \mathrm{C} 19 / 1$} & 1 & $T T$ & 124 & 12 \\
\hline & 2 & $T T$ & 631 & 66 \\
\hline & 3 & $T T$ & 67 & 10 \\
\hline & 4 & $T T$ & 145 & 20 \\
\hline & 5 & $T t$ & 28 & 25 \\
\hline & 6 & $T t$ & 122 & 56 \\
\hline & 7 & $T t$ & 270 & 116 \\
\hline & 8 & $T t$ & 162 & 68 \\
\hline & 9 & $T t$ & 126 & 51 \\
\hline & 10 & $T t$ & 56 & 22 \\
\hline & 11 & $T t$ & 151 & 47 \\
\hline \multicolumn{3}{|c|}{ Total segregating families } & 915 & 385 \\
\hline \multirow[t]{8}{*}{$\mathrm{C} 20 \times \mathrm{C} 19 / 3$} & 1 & $T T$ & 138 & 11 \\
\hline & 2 & $T t$ & 65 & 25 \\
\hline & 3 & $T t$ & 88 & 32 \\
\hline & 4 & $T t$ & 163 & 54 \\
\hline & 5 & $T t$ & 120 & 46 \\
\hline & 6 & $T t$ & 97 & 33 \\
\hline & 7 & $T t$ & 45 & 20 \\
\hline & 8 & $T t$ & 126 & 51 \\
\hline \multicolumn{3}{|c|}{ Total segregating families } & 704 & 261 \\
\hline
\end{tabular}

\section{The excess of non-tolerants}

The majority of results presented here clearly support a single gene model for the inheritance of arsenate tolerance. However, there are a number of anomalous results in every one of which the anomaly is caused by an excess of non-tolerants over that expected under the simple model. There are a number of possible explanations for this excess, which are not mutually exclusive.

(a) Type I errors. In a crossing programme of this size, some anomalous results will inevitably occur by chance and care should be taken not to be misled by these families. However, the fact that the same families seem to turn up regularly in the anomalies implies that chance is unlikely to be their sole cause.

(b) Lethality of homozygotes. An excess of the recessive class can be easily produced if the dominant homozygous class were lethal or had reduced viability. If it is absolutely lethal, then a $2: 1$ ratio, rather than the usual $3: 1$ ratio, is produced in $F_{2}$. There are a number of crosses which fit a $2: 1$ ratio, and so we have examined the data carefully to explore the possibility of a lethal effect. The possible paucity of tolerant homozygotes in the polycrosses between $F_{2}$ plants could be evidence in favour of the reduced viability of homozygotes, however it is obvious that tolerant homozygotes cannot be unconditionally lethal. Chance linkage between a particular $T$ allele and a lethal gene could lead to a sort of heterogeneity in pattern observed here, but we have been unable to find any hypothesis involving linked lethals that could explain any of the polycross results.

(c) Epistasis. Various types of epistatic interactions between two or more major genes are possible that lead to two phenotypes being produced in ratios that would not fit the ratios predicted under a single gene model. We have been unable, however, to find any simple model of epistasis that would account for these data.

(c) Variable penetrance. The scoring of this character (arsenate tolerance) depends on another character (root growth) that is inevitably going to be considerably affected by environmental conditions and genetic background. Environmental and genetic variation will cause variation in root length, which could affect the determination of tolerance. A priori, it is more probable that tolerants will be mistakenly scored as non-tolerants, rather than vice versa because it is more likely that a good root will become inhibited for some reason, than a dead or dying plant will be stimulated.

A measure of the degree of penetrance of tolerance can be obtained by considering the repeatability of the measurement of tolerance. In general, the seedling technique used here does not allow for replication but a number of experiments were conducted in which seedlings were scored for tolerance, and then potted on and scored again as adults. Table 6 a shows the summed results of 10 different families. It is clear that the major- 
Table 6 Comparison of tolerance phenotype determined as seedlings and as adults. (a) Pooled results of 10 families; (b) the results of each family, pooled as to whether individuals scored the same or differently

\begin{tabular}{llrrr}
\hline (a) & & \multicolumn{2}{c}{ Adult phenotype } & \\
\cline { 3 - 4 } & & NT & \multicolumn{1}{c}{ T } & Total \\
\hline Seedling & NT & 143 & 18 & 158 \\
Phenotype & T & 65 & 425 & 480 \\
\hline
\end{tabular}

\begin{tabular}{|c|c|c|c|}
\hline \multirow{2}{*}{$\begin{array}{l}\text { (b) } \\
\text { Family }\end{array}$} & \multicolumn{2}{|c|}{$\begin{array}{l}\text { Comparison of } \\
\text { phenotype as seedling } \\
\text { and adult }\end{array}$} & \multirow{2}{*}{$\begin{array}{l}\text { Percentage } \\
\text { different }\end{array}$} \\
\hline & Same & Different & \\
\hline $\mathrm{C} 20 \times \mathrm{C} 191 / 2$ & 24 & 10 & 29.4 \\
\hline $\mathrm{C} 19 \times \mathrm{G} 21 / 2$ & 45 & 4 & 8.2 \\
\hline $\mathrm{C} 20 \times \mathrm{C} 191 / 7$ & 42 & 4 & 8.7 \\
\hline $\mathrm{C} 19 \times \mathrm{G} 21 / 7$ & 46 & 3 & 6.1 \\
\hline G21 Ext 8 & 84 & 10 & 10.6 \\
\hline G21 Ext 7 & 70 & 18 & 20.5 \\
\hline G21 Ext 17 & 82 & 7 & 11.2 \\
\hline G21 Ext 13 & 68 & 17 & 20.2 \\
\hline $\mathrm{C} 20 \times \mathrm{C} 191 / 3$ & 25 & 3 & 10.7 \\
\hline
\end{tabular}

ity of plants scored the same as adults as they did as seedlings. However, 11.2 per cent of seedlings that scored as non-tolerants as seedlings, scored as tolerants as adults; and 13.2 per cent of seedlings that scored initially as tolerants, scored as non-tolerants later. These two percentages are not significantly different from each other $\left(\chi^{2}=0.476, \mathrm{~ns}\right)$

It is clear, however, that the degree of penetrance is not constant. The mine $\times$ mine crosses, and the backcrosses, $\mathrm{F}_{1} \times$ mine, both show lower rates of production of non-tolerants, and in the polycrosses the proportion of non-tolerants produced by the homozygotes is very variable. The rates of variable scoring for each of the 10 families scored, both as seedlings and adults, are given in Table $6 \mathrm{~b}$. The rates are significantly heterogeneous $\left(\chi^{2}=22.50\right.$, d.f. $\left.=9, P<0.01\right)$, and vary from almost 30 to 6.1 per cent. These results suggest that families may differ in the accuracy with which tolerance may be determined, i.e. that the penetrance of tolerance depends on the genetic background. In the mine population genetic background, the tolerance gene has high penetrance; in the campus genetic background it has lower penetrance. The considerable heterogeneity in penetrance would be caused by segregation of the gene(s) causing variation in penetrance.

A similar variation in the ratios of tolerant to nontolerants has been found in the other two studies of the genetics metal tolerance involving large datasets
(Macnair, 1983; Schat \& ten Bookum, 1992). In both cases the authors ascribed the variation to 'modifiers', genes hypostatic to the tolerance allele that affects the degree of tolerance of tolerant plants. The other gene(s) inferred here could also be described as modifiers, in that their effect appears to be to increase the probability that a plant possessing the tolerance allele manifests the tolerance phenotype.

The finding of a single major gene for tolerance, with tolerance being dominant, has significance for studies on the mechanism and physiology of tolerance. The presence of a major gene suggests that there should be a single primary mechanism for tolerance which is coded for by this gene. The dominance of the character suggests that the mutation is not simply a loss-offunction mutation but rather a change, either to a structural or control gene, which causes the change in both homozygotes and heterozygotes. In other studies (Macnair \& Cumbes, 1987; Meharg \& Macnair, 1990) we have produced evidence that arsenate-tolerant plants have a reduced uptake of arsenate, and postulated that this was a tolerance mechanism. In the accompanying paper (Meharg \& Macnair, 1992a) we show that the major gene for tolerance and reduced arsenate uptake co-segregate, which is further evidence in favour of this hypothesis. Phosphate transport across the plasmalemma is mediated by a specific carrier molecule. This carrier protein is inducible under low phosphate status (McPharlin \& Bieleski, 1987; Cogliatti \& Santa Maria, 1990) and we have shown that in arsenate tolerant plants this inducibility is lost (Meharg \& Macnair, 1992b). It is possible that the mutation studied here is a mutation of the gene control system resulting in the carrier being unconditionally suppressed.

\section{Conclusions}

Thus there is rather good evidence overall that there is a major gene associated with arsenate tolerance in Holcus lanatus, with the tolerant allele being dominant. This gene does not, however, show 100 per cent penetrance in all crosses, and there is evidence that the degree of penetrance varies between families, which suggests that there are other genes affecting this character segregating in these families. These results are consistent with the less extensive results of Watkins \& Macnair (1991) for arsenate tolerance in Agrostis capillaris, where the overall evidence again suggested a major gene for tolerance but with other gene(s) affecting the expression of the character.

The results of all the detailed genetic analysis of metal tolerance in plants so far carried out, therefore, have come to similar conclusions (Macnair, 1983; Schat \& ten Bookum, 1992; Macnair, 1990; this study): 
that there are dominant major genes for tolerance with other genes (modifiers) present as well. These results contradict earlier suggestions of polygenic inheritance for tolerance (Antonovics et al., 1971; Bradshaw \& McNeilly, 1981). As argued elsewhere, however (Macnair, 1991), the results presented here and in the other studies are those expected of a character subjected to strong selection in a novel environment.

\section{Acknowledgements}

Part of this research was supported by SERC grant no GR/F18947, receipt of which is gratefully acknowledged.

\section{References}

ANTONOVICS, J. BRADSHAW, A. D. AND TURNER, R. J. 1971. Heavy metal tolerance in plants. Adv. Ecol. Res., 7, 1-85.

BeDdows, A. R. 1961. Biological Flora of the British Isles: Holcus lanatus L. J. Ecol., 49, 421-430.

BRAdShaW, A. D. AND mCNeIlly, T. 1981. Evolution and Pollution. Edward Arnold, London.

COGLIATTI, D. H. AND SANTA MARIA, G. E. 1990. Influx and efflux of phosphate in roots of wheat plants in non-growth limiting conditions. J. Exp. Bot., 41, 601-607.

EVERITT, B. S. 1977. The Analysis of Contingency Tables. Chapman and Hall, London.

HEWITT, E. J. 1966. Sand and Water Culture Methods Used in the Study of Plant Nutrition. 2nd edn, Technical communication no 22, Commonwealth Agricultural Bureaux, Farnham Royal.

INGRAM, c. 1987. The Evolutionary Basis of the Ecological Amplitude of Plant Species. PhD Thesis, University of Liverpool.

MACNAIR, M. R. 1983. The genetic control of copper tolerance in the yellow monkey flower, Mimulus guttatus. Heredity, 50, 283-293.
MACNAIR, M. R. 1990. The genetics of metal tolerance in natural populations. In: Shaw, J. (ed.) Heavy Metal Tolerance in Plants: Evolutionary Aspects. CRC Press, Boca Raton, pp. 235-254.

MACNAIR, M. R. 1991. Why the evolution of resistance to anthropogenic toxins normally involves major gene changes: the limits to natural selection. Genetic, 84, 213219.

MACNAIR, M. R. AND CUMBES, Q. J. 1987. Evidence that arsenic tolerance in Holcus lanatus $\mathbf{L}$. is caused by an altered phosphate uptake system. New Phytol., 107, 387-394.

MCPHARLIN, I. R. AND BIELESKI, R. C. 1987. Phosphate uptake by Spirodela and Lemna during early stages of phosphate deficiency. Aust. J. Plant. Physiol., 14, 561-572.

MEHARG, A. A. AND MACNAIR, M. R. 1990. An altered phosphate uptake system in arsenate tolerant Holcus lanatus L. New Phytol., 116, 29-35.

MEHARG, A. A. AND MACNAIR, M. R. 1992a. Genetic isolation between arsenate tolerance and the rate of influx of arsenate and phosphate in Holcus lanatus L. Heredity, 69, 336-341.

MEHARG, A. A. AND MACNAIR, M. R. 1992b. Suppression of the high affinity phosphate uptake system: a mechanism of arsenate tolerance in Holcus lanatus L. J. Exp. Bot. 43, 519-524.

PORTER, E. K. AND PETERSON, P. J. 1977. Arsenic tolerance in grasses growing on mine waste. Environ. Poll., 14, 255-265.

SCHAT, H. AND TEN BOOKUM, w. M. 1992. Genetic control of copper tolerance in Silene vulgaris. Heredity, 68, 219-229. SHAw, J. 1990. Heavy Metal Tolerance in Plants: Evolutionary Aspects. CRC Press, Boca Raton.

SYMEONIDIS, L., MCNEILLY, T. AND BRADSHAW, A. D. 1985. Interpopulation variation in tolerance to cadmium, copper, lead, nickel and zinc in nine populations of Agrostis capillaris L. New Phytol., 101, 317-324.

WATKINS, A. J. AND MACNAIR, M. R. 1991. Genetic of arsenic tolerance in Argrostis capillaris L. Heredity, 66, 47-54.

WILKINS, D. A. 1978. The measurement of tolerance to edaphic factors by means of root growth. New Phytol., 80, 623-633. 